\title{
Working in the Culture of High Unemployment: The Impact of Unemployment on Urban Educators
}

\author{
Suzanne M. Selig and Marianne Kugler
}

This study focuses on the ripple effect of high community unemployment on a group of
community educators, the home school counselors. This group plays a crucial role as liaison
between the elementary school child, the parents, and community agencies offering services
for needy children. The impact of remaining employed in an environment of high unemploy-
ment is discussed relative to changes in the general health status of the home school
counselors, changes in their job responsibilities, and perceptions of their effectiveness in
fulfilling those responsibilities. A presentation of the results of this study was made to the
home school counselors, enhancing their awareness of the potential effects of increased
workloads and increased concerns about job security.

\section{INTRODUCTION}

The recent economic recession with its prolonged high unemployment has precipitated a resurgence of research interest among a wide range of behavioral scientists. Such research efforts have studied the consequences of unemployment on the worker, the family, and the community.

Numerous studies have focused on the impact of unemployment on the worker. Studies have examined changes in both mental and physical health status, identifying increased anxiety levels, insomnia, and blood pressure levels as results of unemployment (Rayman and Bluestone, 1982).

Other authors have pointed to behavioral and attitudinal changes which have affected the quality of interpersonal relationships (Liem and Rayman, 1982). Interviews with unemployed workers have revealed feelings of loss of usefulness and self-worth (Maurer, 1979). Feelings of worthlessness are often exacerbated when unemployed workers are dependent on human

Suzanne M. Selig, University of Michigan-Flint; Marianne Kugler, Board of Education, Flint, Michigan. service systems perceived as ineffective and depersonalizing.

The family and other social networks of the unemployed worker are also affected by the reality of unemployment. Although families have the greatest potential for mediating the negative consequences of unemployment, 
they often suffer the most serious difficulties because of the complexity of the family network (S. Cunningham, 1983).

Moen, Cain, and Elder (1983) have described the effects of unemployment on the family as "rippling throughout the family with all family members at risk." Middle-aged heads of households with children living at home have been reported as experiencing the most intense stress caused by unemployment (Rayman and Bluestone, 1982). Children of unemployed workers are particularly affected; they have been reported to show signs of increased moodiness, problems in school, and peer relationship problems.

Communities with high unemployment rates suffer from the negative consequences of unemployment through increased rates of substance abuse, divorce, child and spouse abuse, juvenile delinquency, and suicide. These communities frequently experience increased crime rates and decreased availability of human services. Because unemployment often means loss of health care benefits, there is a decrease in the use of preventive services and an increase in severity of some health problems. Brenner (1976) has predicted increased occurrences in health problems for every one percent increase in unemployment.

The impact of these widespread problems affects the quality of life of all community members, including those individuals living in high unemployment communities who have remained employed. In this environment, workers become more concerned with their own welfare and job security. They often have increased job demands and increased workloads. In human service agencies, these increases may be due to a reduction in the number of fellow workers and an increase in the number of clients with more severe problems.

It is the purpose of this study to describe a group of community educators working in an environment characterized by high and prolonged unemployment, and to discuss the possible impact of this environment on these educators.

\section{The Development of Community Education and the Home School Counselor}

The economy of Flint, Michigan is largely tied to the automobile industry, and therefore the Flint community is significantly affected by the cycles of prosperity and high unemployment which are characteristic of that industry. The Flint community actually initiated the community schools program in 1934, in the middle of the Great Depression, to serve the needs of Depression children. Extensive modifications of the community education structure occurred in the 1950s and 1960s, during a time of great prosperity for Flint, when every garage had two Buicks and three snowmobiles, and every elementary school had five or more support staff positions. It was during this period that the home school counselor positions were created. By the late seventies, the recession had caused extensive layoffs; families of laid off auto workers were requiring increased 
assistance at a time when the schools had fewer available tax dollars to support services for these families.

The concept of community education is embodied in the stated goals of the Flint Community Schools. These goals are based on two underlying purposes: student preparation and total community development, which emphasize the "community education" belief that learning and living are intertwined to the point where the classroom and the community are inseparable, and citizens and agencies are encouraged to join hands in the education process (Preamble, Flint Board of Education Goal Statement). The concept of community education thrusts educators into the community, where major economic shifts have widespread effects.

In the recession of the early 1980 s, educators were encountering students who showed clear indications of stress in a community undergoing serious upheaval. Child abuse, sexual abuse, teen suicides, absenteeism, and crime had all increased. At the same time, the staff members in the schools knew from the Effective Schools research that they must not allow community or family stress to reduce classroom expectations or negatively influence their instructional strategies. Norm-referenced testing results continued to improve during the period studied.

In the elementary community schools, the home school counselor was most intimately involved in direct family and student contact, and at the same time was most directly affected by budget reductions. As the outreach counselor for each school, home school counselors made as many as 100 home calls monthly and regularly sponsored parenting workshops, safety and health clubs, and attendance awards assemblies. By 1980 they also became the resident health experts as nurse positions were reduced. As the sponsor positions disappeared, they also became the formal sponsors of girls' clubs. They became the chief liaison with Protective Services as the psychologists became more involved in special education services. As other community support agencies were experiencing budget reductions, the home school counselors also became the first line for emergency food, clothing, and shelter. Although all of the staff members in the schools were experiencing similar adjustments, the home school counselors had the most intimate daily contact with the families of the unemployed and were most directly affected by the district's reduction in services. For this reason, the present study was initiated.

At the time of the present study, each of the 37 elementary schools in the City of Flint had a home school counselor. The home school counselors ranged from registered nurses to a social service field worker. They were required to have at least two years of college training with some related experience. Up until the fall of 1983, a full time home school counselor was assigned to each elementary program. In fall 1983, however, 34 home school counselors began serving the 37 schools, with split assignments in six of the smaller schools.

Screened for positive physical and mental health, these home school counselors were hired to be nurturers. They facilitated children's access to 
needed community services such as emergency medical care and numerous social services. Because of this crucial role, these educators saw firsthand the crises of unemployed families. In this role, these counselors had a unique opportunity to experience the impact on the community of sustained unemployment and economic depression.

During this period of high community unemployment and increasing workload, home school counselors seemed to be showing signs of increased stress and strain. A systematic examination of their personnel files from 1979-1984 revealed a significant change in their health status (see Table 1). For the 1979-80 and 1980-81 school years, only one home school counselor took a long term absence due to illness. In the subsequent two-year period, however, ten individuals fell into this category. These records indicated a dramatic increase in long term illness among the home school counselors.

The present investigators were interested in explaining the increase in long term absences. Were the increases a function of the "aging" of the home school counselors? Actually, during the 1979-80 school year, eight new home school counselors were added. These additional home school counselors were slightly younger than the previous 29 home school counselors, but were similar to their peers in all other relevant characteristics. Did increased benefits provide an "incentive"' to take more absences due to illness? A review of the health benefits during this period indicated that dental and optical coverage was added to the benefits package, but in all other respects, the health benefits remained stable. It did not seem likely that either "aging" or changes in health benefits encouraged the long term absences. Other factors were then explored.

The study was designed to ascertain the perceptions of home school counselors themselves relative to these health status changes, as well as other factors related to their work environments. Was the "ripple effect" of unemployment extending to the home school counselors?

This report is a descriptive account of the findings of that study, and includes perceptions of home school counselors of the impact of unemployment and severe economic stress on their roles and personal lives. The study results were used to plan training and support activities to prevent the staff burnout discussed so frequently in professional journals and teachers' lounges. Some of the findings were not predicted and did not appear to replicate previous related studies.

\section{METHODOLOGY}

During the spring of 1983, a two-part survey was conducted of all (34) home school counselors. Each part was administered at regularly scheduled monthly meetings. All home school counselors attended each of these meetings and all completed the questionnaires at these meetings, for a 100 percent response rate.

Part One of the survey instrument had previously been administered to the professional staff of a community mental health agency. The questionnaire provided descriptive data as to that staff's perceptions of their job 
TABLE 1. Incidence of Change in Status Among Home School Counselors $(\mathbf{N}=38)^{a}$

\begin{tabular}{l} 
Shange in Status \\
\cline { 2 - 4 }
\end{tabular} S9-80
$\begin{aligned} & \text { Long term absence } \\
& \text { due to illness } \\
& \text { Long term absence } \\
& \text { due to injury }\end{aligned}$
$\begin{aligned} & \text { aData in this table are based on personnel files of home school counselors examined by counselors' } \\
& \text { supervisor. }\end{aligned}$
stress and job satisfaction. ${ }^{1}$ Specifically, Part One included a total of 43
items in several categories including: (a) demographic characteristics of the
home school counselors; (b) descriptive items of current duties and qualita-
tive and quantitative changes of those duties; and (c) items indicating
perceptions of work effectiveness and perception of behavioral and attitu-
dinal changes in fellow employees. Part Two of the survey included four
items which provided more precise focusing of several items in Part One.
Categories for responses to open-ended questions were developed.
Counselor worklogs were used to test the accuracy of their perceptions as
indicated on the survey. After the results were tabulated, extensive discus-
sions were held at two meetings with the home school counselors to discuss
possible conclusions and interpretations.

\section{SUMMARY OF SURVEY RESULTS}

\section{Demographic Characteristics of Respondents}

The home school counselors are all female, the majority of whom $(88 \%)$ are 40 years of age or older. They are nearly equally divided between black and white and almost all are married. Most have children $(85 \%)$ and the vast majority have lived at their current residence for more than five years; nearly one-fourth have been at their current residence more than twenty years. Again, the vast majority have been employed by the Flint Board of Education for more than five years.

\section{Job Responsibility of Respondents}

The counselors stated that of their job responsibilities, the activities they most enjoyed included conferences with individual students, conferences with individual parents at school, home calls on families, and health followups. The majority of home school counselors (79\%) spent more than onehalf of their time devoted to direct student assistance.

\section{Description of Family (Client's) Problems}

The most common problems of home school counselor's family popula- 
tion were related to economic stress: unemployment, food/clothing, and health problems. Almost all (82\%) reported that problems of families had changed over the last year. The most frequently cited problems which had increased were health problems, depression, emergency survival needs, abuse (child or spouse), anxiety, and adjustment reaction to changes in family status.

The majority of home school counselors indicated they had changed their activities to respond to changes in client family problems by having more support groups, and making more referrals to community agencies. However, most did not change their approach in dealing with either parents or staff.

\section{Respondents' Perception of Workload}

Most respondents stated that their workload had increased over the last year with one-half indicating that it had increased "significantly." 'This perception was supported by a comparison of their worklogs with the previous year (see Table 2).

\section{Respondents' Perception of Changes in Fellow Workers}

In response to the question, " Do you feel your peers have experienced specific behavioral and attitudinal changes?" they indicated specifically "loss of idealism," "less committed," "less hopeful," "less creative," "more pessimistic," "more irritable," and "more resistant to change" (see Table 3). The home school counselors reported that over the last year their peers were absent more often (44\%), were more preoccupied with their own welfare on the job (35\%), and were more insecure about their positions (91\%). Nearly one-half reported lower morale among fellow home school counselors, and nearly all (97\%) believed their peers had more health problems over the last year.

We also asked the home school counselors to report any of the same attitudinal and behavioral changes in themselves. Table 3 presents a comparison of perceptions about themselves and their peers.

For every indicator reported in Table 3, home school counselors reported a larger percentage of changes in their fellow counselors than in themselves. For example, seven felt their fellow workers were less committed, but when asked if they felt less committed themselves, only one so indicated. Similarly, twelve home school counselors stated their fellow workers were less

TABLE 2. 1982-1983 Increases in Direct Emergency Service Referrals

\begin{tabular}{lrrr}
\hline & \multicolumn{3}{c}{ Number Reported } \\
\cline { 2 - 4 } Home School Counselor Activity & 1982 & 1983 & Change \\
\hline Emergency Referrals & & & \\
to other agencies & 237 & 564 & $+72 \%$ \\
Finding emergency clothing & 998 & 1408 & $+41 \%$ \\
Finding emergency meals & 347 & 476 & $+37 \%$ \\
\hline
\end{tabular}


TABLE 3. Home School Counselor's Report of Perceived Changes in Other Home School Counselors and in Themselves $(\mathrm{N}=34)$

\begin{tabular}{lrccr}
\hline & \multicolumn{2}{c}{$\begin{array}{c}\text { In Other Home } \\
\text { School Counselors }\end{array}$} & \multicolumn{2}{c}{ In Themselves } \\
\hline Changes & $n$ & $\%$ & $n$ & $\%$ \\
\hline loss of idealism & 11 & 32.4 & 8 & 25.0 \\
less committed & 7 & 20.6 & 1 & 3.1 \\
less hopeful & 12 & 35.3 & 2 & 6.3 \\
less motivated & 4 & 11.8 & 3 & 9.4 \\
less creative & 8 & 23.5 & 4 & 12.5 \\
more pessimistic & 9 & 26.5 & 2 & 6.3 \\
more irritable & 10 & 29.4 & 6 & 18.8 \\
more resistant to & & & & \\
$\quad$ change & 10 & 29.4 & 4 & 12.5 \\
\hline
\end{tabular}

hopeful, while only two reported this for themselves. Nine felt their fellow workers were more pessimistic, but only two stated they themselves were more pessimisic. Ten felt their fellow home school counselors were more resistant to change, while only four reported this for themselves.

We were also interested in assessing whether the reported changes in the work environment, attitude, and behavioral changes were associated with a perception of any change in the home school counselor's own level of effectiveness. We asked the home school counselors "Do you feel your effectiveness as a home school counselor has increased over the last year?" Most (76\%) stated that they felt they were more effective during this time than previously. We also asked if they expected their effectiveness to continue regardless of the economic environment. Nearly all (87.5\%) responded that they did expect to continue being effective.

\section{Follow-Up Discussions With Home School Counselors}

Results of the survey were presented at a monthly meeting of the home school counselors. The implications of the study were also discussed. The counselors were asked for their reactions to the findings presented. They were asked if they thought there was evidence of stress in themselves, even though they had stated/indicated in their responses to the questionnaire that they only saw stress in their fellow workers. They were also asked if they felt they might have been projecting the stress they felt onto their fellow workers.

The discussion was non-threatening for the counselors. Like most educators, this group is selected for its predisposition to discuss feelings openly. They are rewarded for their ability to provide insights, express disappointments, and openly show their emotions.

Most of the home school counselors stated in this discussion that they did recognize increased stress in themselves and regarded this stress as jobrelated. In response to the discussion of projection, the counselors stated that they "liked to regard ourselves as competent . . . it is difficult to admit." They openly admitted this in the discussion, although the written 
responses to the questionnaire were quite different. Another typical comment was that "I was so involved in my workload that I didn't notice."

Some of the home school counselors indicated that although they had not reported signs of stress in themselves, they realized that their family members would have reported that they were under more stress.

In response to the discussion about projecting their stress onto fellow employees, the counselors regarded this projection as "positive." They stated that the projection indicated how much "we care about others." "It also shows how hard we try to not allow job stress to affect our attitudes and the quality of our work with the students."

The discussion of the findings was integrated into an in-service session for the counselors. The discussion enhanced their awareness of the stress they were experiencing, and as a result they were more supportive of each other. One of the activities which they began subsequent to the in-service was keeping a scrapbook of their proudest achievements. Another behavioral change after this in-service was their request for "expert" speakers on the topic of stress. Previously, the counselors had selected other topics for their speakers.

\section{DISCUSSION}

The results of the survey suggest that the home school counselors perceived indicators of burnout in their fellow workers. It appears that their increased workload, as well as increases in the number and severity of family problems with which they dealt, contributed to these signs of burnout.

It is particularly interesting that the home school counselors consistently report these changes in their fellow workers more often than in themselves. One possible explanation for this disparity in reporting is found in the social-psychological literature which addresses the lack of accuracy of respondent's perception and reporting of that perception. One type of bias, "self-serving attribution bias,"' is described as a projection technique which attributes negative qualities and characteristics to others, but not to oneself (Schellenberg, 1974; Hollander, 1976). This is particularly common in situations wherein perception of negative qualities in oneself may be harmful or threatening. It is likely that because $82 \%$ of the home school counselors perceived these changes in others, these changes do exist in the majority of home school counselors. It is also possible that the environment of increased concern about one's own welfare and job security exacerbated the use of this projection technique. Perhaps in less stressful times, the home school counselors would be able to report more accurately about themselves.

This group of home school counselors continued to experience high levels of job satisfaction and positive feelings about their job performance, as indicated by their feeling of effectiveness. However, they had a dramatic increase in the incidence of long term absence due to illness, and although they did not report many indicators of burnout for themselves, they did report them for their fellow home school counselors. 
Intimate involvement with the troubled families of the unemployed included the home school counselors in the "ripple effect" of unemployment. The unemployed worker experiences the initial impact of unemployment, which is soon followed by the impact of the unemployed worker on his family. This study demonstrated that, for at least one group of human service workers who worked closely with unemployed families, the impact of unemployment eventually extended to them as well.

Educational leaders need to be aware of and sensitive to this potential "ripple effect"' as they deal with staff members. Teachers would seem to be especially vulnerable because of their contact with students and parents.

Further research in this area, addressing the teacher group and other types of community stress besides unemployment would seem to be indicated.

\section{NOTES}

1. The questionnaire items to measure job stress and job satisfaction have been used in the "burnout" literature (see Masloch, 1976).

\section{REFERENCES}

Brenner, M. H. (1976) Mental Illness and the Economy. Cambridge: Harvard University Press.

Cunningham, S. (1983). Shock of layoff felt deep inside family circle. APA Monitor 14(1): 10.

Hollander, E. P. (1976) Principles and Methods of Social Psychology. New York: Oxford University Press.

Liem, R., and Rayman, P. (1982). Health and social costs of unemployment. American Psychologist 37(10): 1116.

Masloch, C. (1976). Burned-out. Human Behavior 5(9): 16-24.

Maurer, H. (1979) Not Working, An Oral History of Unemployment. New York: Holt, Rinehart and Winston.

Moen, P., Cain, E. L., and Elder, G. A. (1983). Economical conditions in family life: Contemporary and historical perspectives. In R. Nelson and F. Skidmore (eds.), American Families and the Economy, pp. 213-254. Washington, DC: National Academy Press.

Rayman, P., and Bluestone, B. (1982). The private and social response to job loss: A metropolitan study. Final research report sponsored by the Center for Work and Mental Health, National Institute of Mental Health.

Schellenberg, J. A. (1974). An Introduction to Social Psychology, 2nd ed. New York: Random House. 